\title{
EFFECT OF THERMODYNAMIC AGING ON COLOUR STABILITY, ROUGHNESS AND FLEXURAL STRENGTH OF TWO CAD/CAM LITHIUM DISILICATE GLASS CERAMICS
}

\author{
Shereen Kotb Salem* and Rasha Sayed Asaad**
}

\begin{abstract}
Objective: This study aimed to assess and compare the effect of thermodynamic aging on colour stability, roughness, and flexural strength of two CAD/CAM Li $\mathrm{Si}_{2} \mathrm{O}_{5}$ ceramics.

Materials and Methods: A total of 40 rectangular bar samples were fabricated representing two groups according to type of ceramic (20 samples each). Group I:IPS e.max CAD and Group II:Rosetta SM. Samples of each group were randomly distributed among two subgroups (10 samples each) according to testing procedure and thermodynamic aging condition: Subgroups IA and IIA (10 samples each) act as a control for flexural strength testing in non-aged condition. For Subgroups IB and IIB (10 samples each) both colour and surface roughness (Ra) were measured before thermodynamic aging. Then the samples were subjected again to colour, surface roughness and finally flexural strength (MPa) tests after thermodynamic aging. Data were statistically analyzed.

Results: Neither colour nor flexural strength of the examined ceramic materials were significantly affected by thermodynamic aging. Regarding surface roughness, Rosetta SM was significantly affected by aging, while IPS e.max CAD did not.
\end{abstract}

Conclusion: Concerning the measured parameters Rosetta SM is comparable to IPS e.max CAD being as clinically acceptable even after aging.

KEY WORDS: Rosetta SM, Colour, Roughness, Flexural Strength, Thermodynamic aging.

\section{INTRODUCTION}

Demands for glass ceramics in dentistry increased owing to enhanced improvement in their physical, optical and mechanical properties. Lithium disilicate material is one of the utmost selected ceramics for esthetic restorations due to its outstanding esthetics, excellent biocompatibility, bonding durability and high fracture resistance as well as its simplified fabrication techniques through $\mathrm{CAD} / \mathrm{CAM}$ or pressing, $\mathrm{CAD} / \mathrm{CAM}$ grants it as a unique ceramic material of choice for both clinicians

\footnotetext{
* Associate Professor of Fixed Prosthodontics, Faculty of Dentistry, October 6 University.

** Oral and Maxillofacial Prosthodontic Department, Faculty of Dentistry, King Abdulaziz University, Jeddah, Kingdom of Saudi Arabia.
} 
and laboratories. IPS Empress2 (Ivoclar, Vivadent, Schaan, Liechtenstein) was innovated in 1998, then in 2001 the same manufacturer introduced IPS e.max Press which exhibits better optical and mechanical properties. Finally in 2006, IPS e.max CAD was presented ${ }^{(1)}$. CAD/CAM technique facilitated construction of single visit monolithic ceramic restorations from prefabricated ceramic blocks through computer software (CAD) designing and (CAM) machine milling ${ }^{(2)}$.

For many years IPS e.max series was the most popular widely used lithium disilicate reinforced ceramic. However, new brands were lately introduced as Rosetta (Rosetta, Hass, Gangneung, Korea), AIDITE (Shenzhen, Guangdong, China), T-lithium (Talmax, Curitiba, Brazil), and IRIS (Tianjin, Mainland, China). Manufacturers propose that these new ceramic brands have structural, morphological and mechanical properties similar and comparable to the earliest IPS e.max, but studies that compare these materials are scarce as regards to their mechanical and physical properties ${ }^{(3)}$. In this study, the new ceramic material of choice to be evaluated was Rosetta SM.

Colour stability greatly affects esthetic restorations' clinical outcome. CIE L*a*b* colour order system, was developed by the Commission Internationale de l'Eclairage in 1978. Nowadays, it is commonly used in dental researches ${ }^{(4,5)}$. Colour is defined in terms of $\left(\mathrm{L}^{*}, \mathrm{a}^{*}\right.$, and $\left.\mathrm{b}^{*}\right)$ coordinates, which detect colour within a $3 \mathrm{D}$ colour space. The colour difference $(\Delta \mathrm{E})$ is determined by calculating differences between coordinate values for the same object before and after being subjected to certain conditions $^{(4)}$. So, it has been a routine to assess colour changes using colour measuring devices as spectrophotometers and colorimeters.

In esthetic dentistry, surface roughness of ceramic restoration is a characteristic feature that might enhance surface discoloration, and wear of opposing teeth or ceramic restoration. Dental restorations with high surface roughness are proved to increase plaque accumulation and subsequently dental caries $^{(6)}$. Additionally, irregularly polished surface leads to surface roughness that deteriorates esthetic as well as mechanical properties of a restoration ${ }^{(7)}$. It was recorded that smooth restorations enhance oral comfort and patients' hygiene ${ }^{(8)}$.

Ceramics are brittle materials that can be subjected to breakage under bending forces. To withstand intraoral masticatory forces, ceramic restorations should accomplish sufficient strength. Testing flexural strength is a reliable and relevant method for evaluation of ceramic material longevity and its ability to tolerate chewing forces ${ }^{(9)}$. Materials with high flexural strength provide restorations more resistant to fracture. Monolithic lithium disilicate structure dissipates masticatory stresses all through the whole restoration. Uniform distribution of stresses with no concentration sites is necessary for proper clinical performance as failure stresses of ceramics are not only related to surface porosities and flaws but also to internal disintegration ${ }^{(\mathbf{1 0 )}}$.

Both optical and mechanical characteristics of ceramics are affected by some extrinsic factors as oral environment. So, thermodynamic aging is a commonly used procedure for artificial aging of ceramics mimicking the oral environment, simulating its effect on longevity of restorations giving the chance to examine the behavior of ceramic material intraorally ${ }^{(11-13)}$. Vasiliu et al (2020 $^{(14)}$, studied the effect of thermocycling on the optical properties of CAD/CAM and pressable glass ceramics. They found that aging process influenced milled glass ceramics more than heat pressed ones, additionally they concluded that milled groups showed more significant change than heat pressed regarding optical properties. A study was performed to compare the effect of heat treatment on flexural strength and crystalline structure of IPS e.max CAD and Rosetta SM, the researchers reported that both materials had similar flexural strength and crystalline patterns ${ }^{(1)}$. 
This study aimed to evaluate and compare the effect of thermodynamic aging on colour stability, roughness and flexural strength of IPS e.max CAD and Rosetta SM, with the hypothesis that thermodynamic aging would affect colour stability, roughness, and flexural strength of both ceramics and that there would be no difference in the behavior between the two ceramics.

\section{MATERIALS AND METHODS}

\section{Study Design}

A total of 40 rectangular bar samples $(16 \mathrm{~mm} \mathrm{x}$ $2 \mathrm{~mm} \times 2 \mathrm{~mm}$ ) were constructed and divided into two groups (20 samples each) according to type of ceramic used. Group I: IPS e.max CAD (IvoclarVivadent, Schaan, Liechtenstein) and Group II: Rosetta SM (Rosetta, Hass, Gangneung, Korea). Samples of each group were randomly distributed among two subgroups (10 samples each) according to the testing procedure and thermodynamic aging condition: Subgroups IA and IIA (10 samples each) act as a control for flexural strength testing in non-aged condition. For Subgroups IB and IIB (10 samples each) both colour as well as surface roughness (Ra) were measured for each sample. Then the samples were subjected again to colour, surface roughness and finally to flexural strength (MPa) tests after thermodynamic aging in a chewing simulator.

\section{Samples Preparation}

Both CAD/CAM lithium disilicate partially crystalized blocks (IPS e.max CAD and Rosetta SM) HT/A3.5 C14 were sawed using ISOMET 4000 (Buehler, Lakebluff.USA) with water coolant to obtain rectangular bars $(16 \mathrm{~mm} \times 2 \mathrm{~mm} \times 2 \mathrm{~mm})$. A digital caliper was then used to check these dimensions. Samples of both groups (20 samples each) were fully crystalized Programat P310 (Ivoclar Vivadent) following manufacturers' recommended firing cycles with maximum firing temperature $850^{\circ} \mathrm{C}$. Samples were fixed on the tray during firing using vita firing paste. Samples were finished using finishing wheel (green wheel of the Eve Diapol, EVE Ernst Vetter GmbH Rastatter Str, Pforzhei) then cleaned using steam jet. Finally, all samples were glazed using IPS Ivoclor glaze (Ivoclar, vivadent,) as recommended by the manufacturer.

\section{Testing procedures}

\section{Thermodynamic aging}

Samples of subgroups IB and IIB were subjected to thermodynamic aging which was carried out using the four stations multi-modal ROBOTA chewing simulator integrated with thermo-cyclic protocol operated on servo-motor (Model ACH-09075DC-T, AD-TECH Technology CO., LTD., Germany). The samples were inserted in chemically cured acrylic mold which was fixed to lower component of the simulator. Dynamic aging was done by loading samples vertically with $50 \mathrm{~N}$ by a sliding stainless steel sphere-shaped piston for 75000 cycles at 3 $\mathrm{Hz}$ to clinically simulate 6 months of chewing condition $^{(15)}$. The piston vertical movement was 2 $\mathrm{mm}$ (with rising speed of $90 \mathrm{~mm} / \mathrm{s}$ and descending speed of $40 \mathrm{~mm} / \mathrm{s}$ ) and its horizontal movement was $2 \mathrm{~mm}$ (with forward speed of $90 \mathrm{~mm} / \mathrm{s}$ and backward speed of $40 \mathrm{~mm} / \mathrm{s}$ ) at a torque of 2.4 N.m. Simultaneous thermal aging was carried out by thermo-cycling in water bath at $5^{\circ} \mathrm{C} / 55^{\circ} \mathrm{C}$ and dwell time 60 seconds.

\section{Colour Measurements Test}

The colour coordinates were measured for all samples of Subgroups IB and IIB before and after aging using a spectrophotometer (X-Rite, model RM200QC, Neu-Isenburg, Germany) with the settings of $4 \mathrm{~mm}$ aperture size and samples were aligned with the device. To ensure repetition of colour measurements in the same area per sample and to stop any external light source from entering, a white Teflon holder was used. Colour values $\left(L^{*}, a^{*}, b^{*}\right)$ of samples were measured on each side for three times over white background. 
In this study, colour difference $\Delta \mathrm{E}^{*}$ between both ceramic materials was calculated from this equation $^{(16)}$ :

$$
\Delta \mathrm{E}^{*}=\left[\left(\Delta \mathrm{L}^{*}\right)^{2}+\left(\Delta \mathrm{a}^{*}\right)^{2}+\left(\Delta \mathrm{b}^{*}\right)^{2}\right]^{1 / 2}
$$

\section{Assessment of Surface Roughness (Ra)}

A 3D-surface analyzer system was used for contactless quantitative analysis for surface roughness of the tested samples before and after thermodynamic aging(17). All the samples of subgroups IB and IIB were photographed using USB Digital microscope with a built-in camera (Scope Capture Digital Microscope, Guangdong, China). Images were taken with resolution $1280 \mathrm{X}$ 1024 pixels. They were then magnified $120 \mathrm{X}$ and cropped (350 X 400pixels) using Microsoft office picture manager. Analysis of the cropped images and calculation of average (Ra) in $\mu \mathrm{m}$ was done by WSxM software (Version 5 develop 4.1, Nanotec, Electronica, SL) ${ }^{(\mathbf{1 8})}$. Three different areas were measured per sample ${ }^{(\mathbf{1 9})}$.

\section{Three-point flexural strength testing}

Samples of all groups were subjected to flexural test. Subgroups IA and IIA were tested without thermodynamic aging to act as control for aged subgroups, while IB and IIB subgroups were tested for flexural strength after thermodynamic aging. Samples were placed in an Instron machine (Model 3345; Instron Industrial Products, Norwood, MA, USA) over two stainless steel rods $(13 \mathrm{~mm}$ span length) to support the sample. Compressive load was applied with a loadcell of $5 \mathrm{kN}$ over the center of ceramic sample at a crosshead speed of $1 \mathrm{~mm} / \mathrm{min}$ till fracture. Data were recorded utilizing computer software (Instron ${ }^{\circledR}$ Bluehill Lite Software)

The value of (FS) was calculated using this formula: FS (ó) =3F (L)/ $\mathbf{2} \mathbf{w h}^{2}$

FS: limiting stress at which failure is obtained.

F: Maximum load at the point of fracture,

$\mathbf{L}$ : Span, w: Sample width and $\mathbf{h}$ : Sample height.

\section{Statistical Analysis}

For comparing the two groups in non-related samples, independent sample t-test was used, while paired sample t-test was used for comparing the two groups in related samples. Significance level was set at $\mathrm{P} \leq 0.05$. Statistical analysis was done by $\mathrm{IBM} \otimes$ SPSS ${ }^{\circledR}$ Statistics Version 20 for Windows.

\section{RESULTS}

Collected data were explored for normality using Kolmogorov-Smirnov and Shapiro-Wilk tests and showed parametric (normal) distribution.

\section{Colour}

There was no statistically significant difference between both subgroups IB and IIB. Subgroup IIB had a higher $\Delta \mathbf{E}$ than IB. Table $\mathbf{1}$

TABLE (1): $\Delta \mathrm{E}$ values of different subgroups.

\begin{tabular}{|c|c|c|}
\hline \multirow{2}{*}{ Subgroup } & \multicolumn{2}{|c|}{$\Delta \mathrm{E}$} \\
\cline { 2 - 3 } & Mean & SD \\
\hline IB & $3.07^{\mathrm{a}}$ & 1.51 \\
\hline IIB & $3.46^{\mathrm{a}}$ & 0.82 \\
\hline p-value & \multicolumn{2}{|c|}{$\mathbf{0 . 5 6 0} \mathrm{ns}$} \\
\hline
\end{tabular}

Same letters denote no significant difference. ns: nonsignificant at $(p>0.05)$

\section{Surface roughness:}

\section{Effect of aging on the materials:}

No statistically significant difference was recorded within subgroup IB. It had higher mean value before thermodynamic aging. While, there was a statistically significant difference within subgroup IIB. Higher mean value was recorded after thermodynamic aging. Tables $\mathbf{2}$ and $\mathbf{3}$

\section{Comparing the effect of aging on both materials:}

Before aging, a statistically significant difference was recorded between subgroups IB and IIB. Subgroup IB showed higher mean value. While after aging, no statistically significant difference was recorded between the two subgroups. Subgroup IIB showed higher mean value. Tables $\mathbf{2}$ and $\mathbf{3}$ 
TABLE (2): Surface roughness mean values and SD of different subgroups.

\begin{tabular}{|c|c|c|c|c|c|}
\hline \multirow{2}{*}{ Subgroups } & \multicolumn{5}{|c|}{ Surface roughness } \\
\cline { 2 - 6 } & \multicolumn{2}{|c|}{ Before thermodynamic aging } & After thermodynamic aging & \multirow{2}{*}{ p-value } \\
\cline { 2 - 6 } & Mean & SD & Mean & 0.00153 & \multirow{2}{*}{$\mathbf{0 . 2 0 5 n s}$} \\
\hline IB & $0.25362^{\mathrm{aA}}$ & 0.00175 & $0.25282^{\text {aA }}$ & 0.00172 & $\mathbf{0 . 0 2 1 *}$ \\
\hline IIB & $0.25052^{\mathrm{bB}}$ & 0.00138 & $0.25288^{\text {aA }}$ & $\mathbf{0 . 9 4 5 n s}$ \\
\hline
\end{tabular}

Different small letters in same column and capital letters in same row denote significant difference. *; significant at (p<0.05), ns:non-significant,

TABLE (3): Surface roughness topography of the two tested materials.

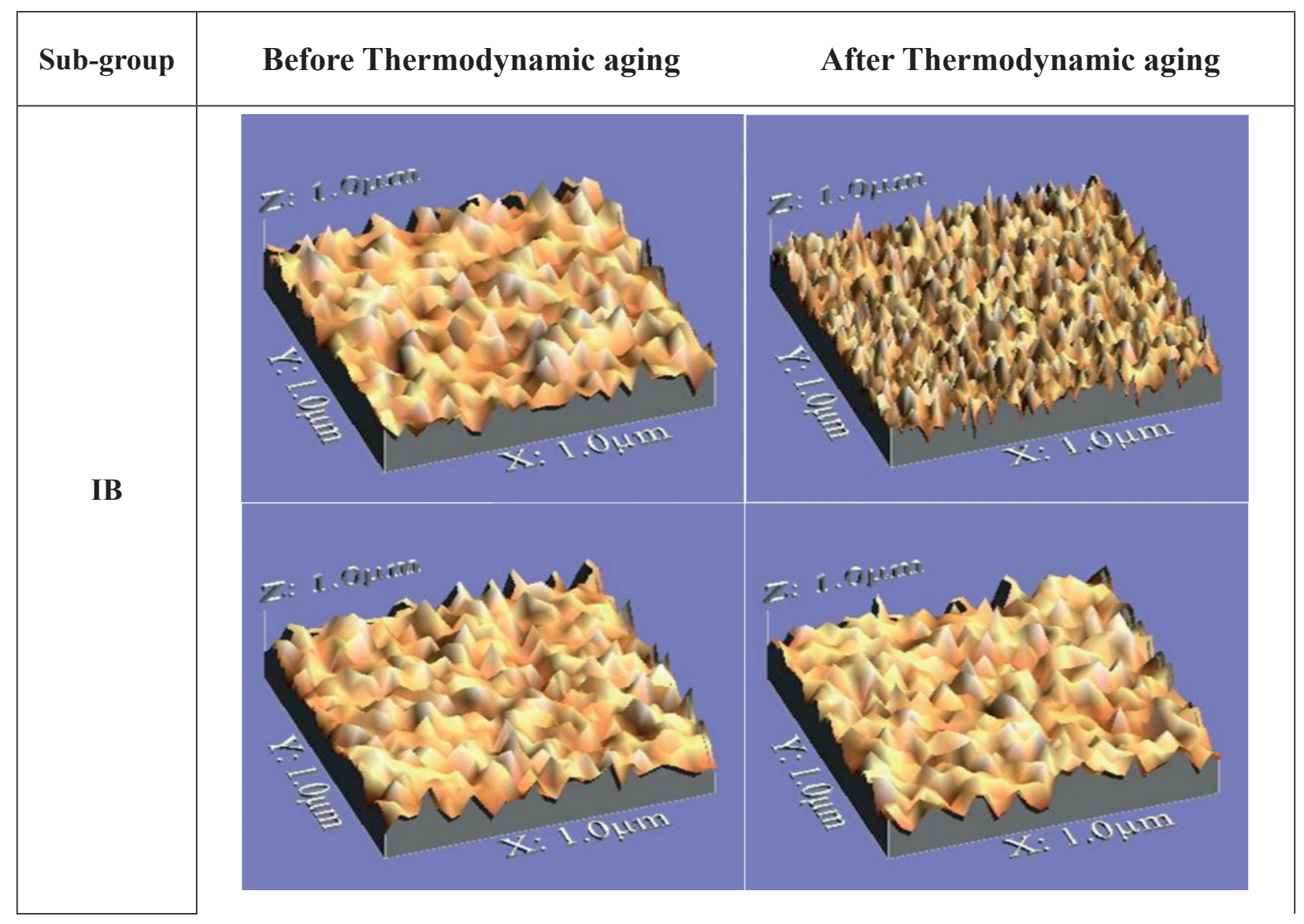




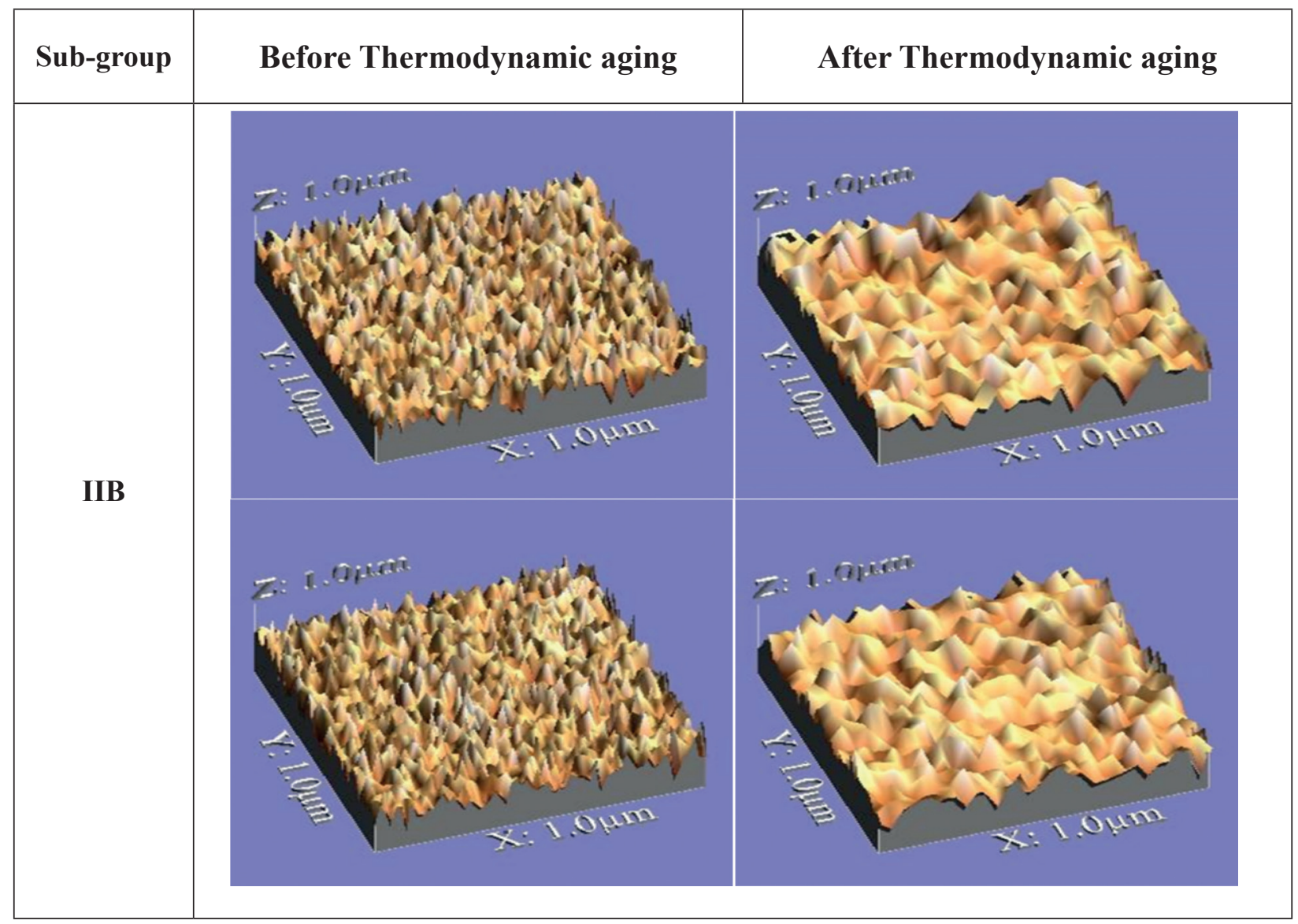

\section{Flexural strength:}

A statistically significant difference was recorded between Groups I and II before and after aging. Group I showed higher mean values before and after aging. There was no statistically significant difference within groups. Table 4

TABLE (4): Flexural strength mean values and SD of different groups.

\begin{tabular}{|c|c|c|c|c|c|}
\hline \multirow{3}{*}{ Groups } & \multicolumn{5}{|c|}{ Flexural strength } \\
\hline & \multicolumn{2}{|c|}{$\begin{array}{c}\text { Subgroup A } \\
\text { Before thermodynamic aging }\end{array}$} & \multicolumn{2}{|c|}{$\begin{array}{c}\text { Subgroup B } \\
\text { After thermodynamic aging }\end{array}$} & \multirow[t]{2}{*}{ p-value } \\
\hline & Mean & SD & Mean & SD & \\
\hline $\begin{array}{c}\text { Group I } \\
\text { IPS e } \max C A D\end{array}$ & $377.25^{\mathrm{aA}}$ & 10.61 & $400.80^{\mathrm{aA}}$ & 16.33 & $0.052 \mathrm{~ns}$ \\
\hline $\begin{array}{c}\text { Group II } \\
\text { Rosetta SM }\end{array}$ & $313.58^{\mathrm{bA}}$ & 18.92 & $338.64^{\mathrm{bA}}$ & 29.91 & $0.206 \mathrm{~ns}$ \\
\hline p-value & \multicolumn{2}{|c|}{$0.001 *$} & \multicolumn{2}{|c|}{$0.011 *$} & \\
\hline
\end{tabular}

Different small letters in same column and capital letters in same row denote significant difference. *; significant at (p<0.05), ns:non-significant, 


\section{DISCUSSION}

In this study CAD/CAM ceramic blocks were used, as their standardized manufacturing process results in blocks with more homogeneous structure, reliable quality and better mechanical and physical properties ${ }^{(20,21)}$. For many years, CAD/CAM lithium disilicate ceramic blocks were exclusively produced by only one manufacturer (Ivoclar Vivadent, Schaan, Liechtenstein). But, lately (Rosetta SM, Hass, Gangneung, Korea) has emerged and needs to be compared to IPS e.max CAD to be safely and alternatively used with it as the manufacturer and few researchers claim that it has comparable properties to IPS e.max ceramic. Optical, physical, and mechanical properties decide the success rate of any ceramic restoration. That is why in this study, colour stability, surface roughness and flexural strength of both ceramics were tested before and after thermodynamic aging.

Thermo-mechanical aging might result in a significant clinical representation. The adverse intraoral environment was simulated by exposing the samples to artificial thermodynamic aging to evaluate alterations over a period of time, its influence on colour, roughness and flexural strength $^{(22)}$.Chewing simulator was used as it can imitate the dynamic process and forces in oral cavity that may cause failure of ceramic restoration. Also, temperature and water decrease values of materials strength. Chewing simulators have the ability to offer reliable results. They are regarded as one of the best methods for inspecting flexural strength of different dental ceramic materials ${ }^{(23)}$. Therefore, thermodynamic aging performed in current study could be considered as a satisfactory simulation of clinical conditions.

In this study colour was assessed using a spectrophotometer to eliminate individual interpretation of visual colour similarity. CIElab system was used to detect minor difference in colour where $\Delta \mathrm{E}$ represents the numerical values between the 3 coordinates $\mathrm{L}^{*} \mathrm{a} * \mathrm{~b} *$ and demonstrates the colour change values ${ }^{(24,25)}$.

Surface roughness is considered one of the most clinically relevant tests to evaluate ceramic restorations' mechanical performance as it highly affects their clinical behavior. Rough surface may reduce materials' fracture resistance due to creation and propagation of surface micro-cracks ${ }^{(14)}$. In this study a quantitative analysis for surface roughness was done to assess the impact of thermodynamic aging on the tested ceramics.

Flexural strength is considered as a principal determinant of brittle materials' mechanical properties. The three-point flexural strength testing method was performed in this study as it was approved by ISO 6872 standard (2008) for dental ceramics $^{(26)}$. Three-point test is often used due to its simplicity. Difference in samples shapes and surface flaws may result in only $10 \%$ variation of results. Rounding edges and good polishing reduce the effect of surface flaws and improve test reproducibility for $20-30 \%{ }^{(23)}$.

Results showed statistically and clinically nonsignificant colour change in samples before and after thermodynamic aging where the recorded $\Delta \mathrm{E}$ for both subgroups IB and IIB were less than 3.7 which is considered as clinically acceptable ${ }^{(27)}$. Researchers ${ }^{(14,27,28)}$, recorded significant change in colour coordinates of IPS e.max CAD due to aging ,yet they still lie within the clinically acceptable range. They related this to the material itself not to the selected shade. They also recorded that glazing of ceramic samples had a significant effect on maintenance of colour stability and restoration protection from stains ${ }^{\mathbf{( 1 4}, \mathbf{2 9})}$. According to Jones et al (2004) ${ }^{(30)}$, Ra values up to $0.28 \mu \mathrm{m}$ are considered clinically accepted. In the current study roughness results of the tested materials were in the acceptable clinical range. Aging did not show significant effect on surface roughness of IPS e.max CAD, but it affected Rosetta SM significantly. Comparing 
both materials although IPS e.max CAD showed significantly higher surface roughness before aging compared to Rosetta SM, yet after aging there was no significant difference between both materials. These results might be explained by the IPS scientific documentation by Ivoclar which states that milling $\mathrm{CAD} / \mathrm{CAM}$ ceramic leaves detectable surface roughness that is dependent on the milling process as well as the grain size and geometry of the milling tools. Thus, the initial surface roughness after CAM processing does not depend on the used ceramic material. That is why they recommend finishing according to manufacturer's instructions even if the restoration will be glazed later as glazing solely is not enough ${ }^{(31)}$.

This can be supported by the SEM images presented by Kang et al (2013) ${ }^{(\mathbf{1})}$, showing initially similar crystalline patterns in IPS e.max CAD and Rosetta SM, yet following crystallization; more dense crystalline microstructure was formed with crystal size increased up to $2-3 \mu \mathrm{m}$ for IPS e.max CAD while 1-2 $\mu \mathrm{m}$ for the Rosetta SM. Also, Porto et al (2019) $)^{(32)}$, recorded rough surface of IPS e.max CAD with peaks and valleys, with cracks and hackles in small areas. They also found that $\mathrm{CAD} / \mathrm{CAM}$ ceramics were not affected by aging and performed better after hydration. However on the contrary other researchers ${ }^{(14,33)}$, found that IPS e.max CAD registered significant changes in surface roughness after thermocycling.

Concerning the effect of aging on flexural strength of both IPS e.max CAD and Rosetta SM, there was an insignificant increase after aging of both materials. Also, IPS e.max CAD showed a significantly higher flexural strength before and after aging in comparison to Rosetta SM. Taking into consideration that the initial strength of CAD/ CAM ceramic block might be correlated to the probability of crack formation and crazing due to process of milling and that the final mechanical properties of glass ceramics are determined by intrinsic and extrinsic factors ${ }^{(34,35)}$. Intrinsic factors include size, number, geometry, and homogeneity (distribution pattern) of the reinforcing crystals. In addition to thermal expansion/contraction matching between the crystal phase and glassy matrix. While extrinsic factors affect the long-term success of the material. Extrinsic factors include fabrication and oral environmental conditions like humidity (stress corrosion), $\mathrm{pH}$ level, thermo-shocks, cyclic loading and peak loads when accidently biting on hard objects during mastication ${ }^{(36)}$.

IPS e.max CAD microstructure contains small interlocking randomly oriented plateletlike crystals. These crystals result in deflecting, blunting or branching cracks, thus, arresting their propagation within the material causing high flexural strength ${ }^{(37)}$. It consists of approximately $70 \%$ by volume fine grained $\left(\mathrm{Li}_{2} \mathrm{Si}_{2} \mathrm{O}_{5}\right)$ crystals in glass matrix. Mechanical and optical properties of ceramics are greatly influenced by microstructural parameters as grain size and porosity ${ }^{\left({ }^{(38,39)}\right.}$. Li et al $\mathbf{( 2 0 1 6}^{(\mathbf{4 0 )}}$, investigated the influence of crystal size on mechanical properties of lithium disilicate ceramics. They reported that flexural strength recorded a prominent change with increasing crystal size. They proved the presence of micro-residual compressive stresses in the crystals due to variation in thermal expansion between the crystalline phase and glassy matrix. Residual stresses increased as crystal size increased creating balancing tensile stresses in the glass matrix. So crystal size performed interlocking as well as micro-residual stress effects. Thus, it had a dual effect on flexural strength of the glassceramic. However, these stresses within the glassy matrix would counteract the crystals "interlocking effect" that might cause strength degradation.

Results were in agreement with Peampring and Sanohkan (2014) $)^{(41)}$, who concluded that thermodynamic aging did not significantly affect flexural strength of IPS e.max CAD with higher mean values after aging. They attributed these results to the large amount of reinforcing crystals which enhances strengthening effect that resulted from crack deflection and bridging ${ }^{(42,43)}$. 
These results came on the contrary to kang et $\mathbf{a l}(\mathbf{2 0 1 3})^{(\mathbf{1})}$, who recorded similar flexural strength results for IPS e.max CAD and Rosetta SM. They attributed this to XRD specifying main crystals peak locations of lithium metasilicate and disilicate, as well as the background intensities of Rosetta SM and IPS e.max CAD to be similar to each other in spite of the difference in crystals size after crystallization. However, they recorded larger crystals in IPS e.max CAD compared to Rosetta SM. They reported that variation in crystals size might be seen in the same product according to opacity or shade. Heat treatment, base glass composition, and nucleating agents greatly affects crystals' size among different factors ${ }^{(44)}$. Also, some researchers concluded that thermal stressing may cause tensions within the material which consequently slows down crack growth $^{(32,45)}$.

Porto et al $(\mathbf{2 0 1 9})^{(32)}$, recorded a remarkable rise in flexural strength of lithium disilicate ceramic after one week of storage in water.

However, controversial ceramics' flexural strength results might be attributed to the influence of multiple factors on its measurements, as samples dimensions, polishing technique and tools, stress rate, environmental conditions and testing method as well ${ }^{(46)}$.

Therefore, the hypothesis is partially accepted as the thermodynamic aging insignificantly affected colour stability and flexural strength of the tested materials while it significantly affected the surface roughness of Rosetta SM.

\section{CONCLUSION}

Within the limitations of this study it was concluded that

Concerning the measured parameters Rosetta $\mathrm{SM}$ is comparable to IPS e.max CAD being as clinically acceptable even after aging.

\section{REFERENCES}

1. Kang SH, Chang J, Son HH. Flexural strength and microstructure of two lithium disilicate glass ceramics for CAD/ CAM restoration in the dental clinic. Restor. Dent. Endod. 2013;38(3):134-40.

2. Ng J, Ruse D, Wyatt C.A comparison of the marginal fit of crowns fabricated with digital and conventional methods. J Prosthet. Dent.2014:112:555-60.

3. Tavares LN, Zancope K, Slva ACA, Raposo LHA, Soares $\mathrm{CJ}$, Neves FD. Microstructural and mechanical analysis of two CAD-CAM lithium disilicate glass-reinforced ceramics. Braz. Oral Res.2020;34:e004.

4. Douglas RD, Steinhauer TJ, Wee AG. Intraoral determination of the tolerance of dentists for perceptibility and acceptability of shade mismatch. J Prosthet. Dent.2007; 97: 200-8.

5. Elmaria A, Goldstein G, Vijayaraghavan T, Legeros RZ, Hittelman EL. An evaluation of wear when enamel is opposed by various ceramic materials and gold. J Prosthet. Dent. 2006; 96: 345-53.

6. Hanganu SC, Armencia AO, Murariu AM, Hanganu LC. Surface and Depth Modification Assessment for Biomaterials used in Restorative Dentistry. Digest Journal of Nanomaterials and Biostructures 2013;8(2): 885 - 98.

7. Cavalcante LM, Masouras K, Watts DC, Pimenta LA, Silikas N. Effect of nanofillers' size on surface properties after toothbrush abrasion. Am. J Dent. 2009; 22:60-64.

8. Kantorski KZ, Scotti R, Valandro LF. Surface roughness and bacterial adherence to resin composites and ceramics. Oral Health Prev. Dent.2009; 7:29-32.

9. Charlton DG, Roberts HW, Tiba A. Measurement of select physical and mechanical properties of 3 machinable ceramic materials. Quintessence Int. 2008; 39:573-79.

10. Siarampi E, Kontonasaki E, Papadopoulou L, Kantiranis N, Zorba T, Paraskevopoulos KM, Koidis P. Flexural strength and the probability of failure of cold isostatic pressed zirconia core ceramics. J Prosthet Dent. 2012; 108:84-95.

11. Hamza TA, Alameldin AA, Elkouedi AY, Wee AG. Effect of artificial accelerated aging on surface roughness and color stability of different ceramic restorations. Stomatol. Dis Sci. 2017;1: 8-13.

12. Dos Santos PH, Catelan A, Albuquerque Guedes AP, Umeda Suzuki TY, de Lima Godas AG, Fraga Briso A.L, 
Bedran-Russo AK. Effect of thermocycling on the roughness of nanofilm, microfilm and micro-hybrid composites. Acta Odontol Scand. 2015; 73:176-81.

13. Subaşı MG, Alp G, Johnston WM, Yilmaz B. Effects of fabrication and shading technique on the color and translucency of new-generation translucent zirconia after coffee thermocycling. J. Prosthet. Dent. 2018;120: 603-8.

14. Vasiliu RD, Porojan SD, Bîrdeanu MI, Porojan L. Effect of thermocycling, surface treatments and microstructure on the optical Properties and roughness of CAD/CAM and heat-pressed glass ceramics. Materials. 2020;13(2):381.

15. Nawafleh N, Hatamleh M, Elshiyab S, Mack F. Lithium disilicate restorations fatigue testing parameters: A Systematic Review. J Prosthodont. 2016; 25: 116-26.

16. Chu SJ, Devigus A, Mieleszko AJ. Fundamentals of Color: Shade Matching and Communication in Esthetic Dentistry. Chicago, IL, Quintessence Pub. Co., 2010; $2^{\text {nd }}$ ed.

17. Ossama B. Abouelatta. 3D Surface Roughness Measurement Using a Light Sectioning Vision System. Proceedings of the World Congress on Engineering 2010 Vol. I.

18. Horcas I, Fernandez R, Gomez JM, Colchero J, GomezHerrero J, and Baro AM, Review of Scientific Instruments. 2007;78; 013705.

19. Kakaboura A, Fragouli M, Rahiotis C, Silikas N. Evaluation of surface characteristics of dental composites using profilometry, scanning electron, atomic force microscopy and gloss-meter. J Mater Sci Mater Med. 2007; 18: 155-63.

20. Hickel R, Manart J. Longevity of restorations in posterior teeth and reasons for failure. J Adhes Dent. 2001; 3:45-64.

21. Manhart J, Chen H, Hamm G, Hickel R. Buonocore Memorial Lecture. Review of the clinical survival of direct and indirect restorations in posterior teeth of the permanent dentition. Oper Dent. 2004; 29:481-508.

22. Stewardson DA,Shortall AC, Marquis PM.The effect of clinically relevant thermocycling on flexural properties of endodontic post materials. J Dent.2010;38:437-42.

23. Mijoska A, Popovska M. Evaluation of different in vitro testing methods for mechanical properties of veneer ceramics. DE GRUYTER J, Sec. Med. Sci., 2015; 36(1):225-30.

24. Macentee M, Lakowski R. Instrumental color measurement of vital and extracted human teeth. J Oral Rehabil 1981; 8:203-8.

25. Ishikawa-Nagai S, Sato RR, Shiraishi A, Ishibashi K. Using a computer color matching system. A newly developed spectrophotometer designed for clinical application. Int $\mathrm{J}$ Prosthodont 1994; 7:50-55.

26. (2008) International Standards Organization (ISO). Dentistry-ceramic materials, Amendment; ISO 6872.

27. Palla ES, Kontonasaki E, Kantiranis N, Papadopoulou L, Zorba T, Paraskevopoulos KM, Koidis P. Color stability of lithium disilicate ceramics after aging and immersion in common beverages. J Prosthet Dent 2018; 119:632-42.

28. Haralur SB, Alqahtani NRS, Mujayri FA. Effect of hydrothermal aging and beverages on color stability of lithium disilicate and zirconia based ceramics. Medicina 2019; 55(11), 749 .

29. Anusavice, K. Phillips' Science of Dental Materials, 11th ed.; Elsevier: London, UK, 2003.

30. Jones CS, R. Billington W, Pearson GJ. The in vivo perception of roughness of restorations, British Dental Journal. 2004; 196(1): 42-45.

31. Scientific Documentation IPS e.max CAD Ivoclar Vivadent AG. Available from: http://www.ivoclarvivadent.

32. Porto TS, Roperto RC, Akkus A, Akkus O, Teich S, Faddoul F, Porto-neto ST, Campos EA. Effect of storage and aging conditions on the flexural strength and flexural modulus of CAD/CAM materials. Dent Mater J 2019; 38(2): 264-70.

33. Ardu S, Feilzer AJ, Devigus A, Krejci I. Quantitative clinical evaluation of esthetic properties of incisors.Dent. Mater. 2008, 24, 333-40.

34. Harrer W, Danzer R, Supancic P. Influence of the surface quality of ceramic specimens on the results of B3B-Tests. 18th European Conference on Fracture. 2010. Dresden, Germany.

35. Harrer W, Danzer R, Morrell R. Influence of surface defects on the biaxial strength of a silicon nitride ceramicIncrease of strength by crack healing. J European Ceram Soc 2012; 32:27-35

36. Denry I, Holloway JA. Ceramics for dental applications: A review. Materials. 2010; 3(1):351-68

37. Goonawardhana D. "IPS E.MAX". EC Dental Science 9.3 (2017): 106-23.

38. Zum Gahr KH, Bundschuh W, Zimmerlin B. Effect of grain size on friction and sliding wear on oxide ceramics. Wear 1993; 162:269-79. 
39. He Y, Winnubst L, Burggraaf AJ, Verweij H, van der Varst PGT, de With B. Grain size dependence of sliding wears tetragonal zirconia polycrystals. J. Am. Ceram. Soc. 1996; 79:3090-96.

40. Li D, Quo JW, Wang XS, Zhang SF. Effects of crystal size on the mechanical properties of a lithium disilicate glassceramic. Materials Science and Engineering A. 2016; (669): 332-39.

41. Peampring C \& Sanohkan S.Effect of thermocycling on flexural strength and weilbull statistics of machinable glass-ceramic and composite resin. J Indian Prosthodont Soc 2014; 14(4): 376-80.

42. Tsitrou EA, Northeast SE, van Noort R. Brittleness index of machinable dental materials and its relation to the marginal chipping factor. J Dent. 2007;35(12):897-902.
43. Höland W, Schweiger M, Watzke R, Peschke A, Kappert H. Ceramics as biomaterials for dental restoration. Expert Rev Med Devices. 2008;5(6):729-45.

44. Kuzielova E, Palou M, Kozankova J. Crystallization mechanism and bioactivity of lithium disilicate glasses in relation to $\mathrm{CaO}, \mathrm{P}_{2} \mathrm{O}_{5}, \mathrm{CaF}_{2}$ addition. Ceram Silik 2007; 51:136-41.

45. Basílio MA, Cardoso KV, Antonio SG, Rizkalla AS, Junior GCS, Filho JNA, Effects of artificial aging conditions on yttria-stabilized zirconia implant abutments. J Prosthet. Dent. 2016; 116(2): 277-285

46. Lin WS, Ercoli C, Feng C, Morton D. The effect of core material, veneering porcelain, and fabrication technique on the biaxial flexural strength and weibull analysis of selected dental ceramics. J Prosthodont.2012;21(5):353-62. 